\title{
The Effect of Glenohumeral Internal Rotation Deficit on the Isokinetic Strength, Pain, and Quality of Life in Male High School Baseball Players
}

\author{
Jinyoung Lee, $\mathrm{MD}^{1}$, Li-Na Kim, MD ${ }^{1}$, Hongsun Song, $\mathrm{PhD}^{2}$, \\ Sunghwan Kim, $\mathrm{MD}^{1}$, Seungseok Woo, $\mathrm{MS}^{3}$
}

\author{
${ }^{1}$ Department of Physical Medicine and Rehabilitation, Sahmyook Medical Center, Seoul; \\ ${ }^{2}$ Korea Institute of Sports Science, Seoul; ${ }^{3}$ Institute of Health and Exercise, Seoul National University, Seoul, Korea
}

\begin{abstract}
Objective To investigate the effects of glenohumeral internal rotation deficit (GIRD) on the isokinetic strength, body pain, and the quality of life in male high school baseball players of Korea.

Methods Fifty-six male high school baseball players were divided into either group A (GIRD $\left.\geq 20^{\circ}, \mathrm{n}=12\right)$ or group $\mathrm{B}$ $\left(\mathrm{GIRD}<20^{\circ}, \mathrm{n}=44\right)$. The range of motion in the shoulder and the isokinetic strength were measured. Questionnaires were administered regarding the body pain location by using the visual analogue scale, and the quality of life was measured by using the SF-36 Form.

Results All subjects had increased external rotation range of motion and decreased internal rotation in the throwing shoulder. The incidence of GIRD $\left(\geq 20^{\circ}\right)$ was $21.43 \%$ in the present study. In the isokinetic strength test, a significantly weaker muscular state at an angular velocity of $180^{\circ} / \mathrm{s}$ was observed in group A, compared to group B. For the comparison of the pain, the frequency of shoulder pain was higher (33.93\%) than other body pain, among the study subjects.

Conclusion GIRD is one of the main risk factors of glenohumeral joint damage, and it is correlated with reduced isokinetic strength and quality of life. High school baseball players will need appropriate shoulder rehabilitation programs for the improvement in their quality of life and performance.
\end{abstract}

Keywords Glenohumeral joint, Shoulder joint, Baseball, Shoulder pain, Quality of life

Received July 10, 2014; Accepted September 29, 2014

Corresponding author: Li-Na Kim

Department of Physical Medicine and Rehabilitation, Sahmyook Medical Center, 82 Mangu-ro, Dongdaemun-gu, Seoul 130-711, Korea

Tel: +82-2-2210-3135, Fax: +82-2-2210-3133, E-mail: magiclina@naver. com

(c) This is an open-access article distributed under the terms of the Creative Commons Attribution Non-Commercial License (http://creativecommons. org/licenses/by-nc/3.0) which permits unrestricted noncommercial use, distribution, and reproduction in any medium, provided the original work is properly cited.

Copyright $\odot 2015$ by Korean Academy of Rehabilitation Medicine

\section{INTRODUCTION}

Glenohumeral joint is a common site for injury, which accounts for $>30 \%$ of all injuries in overhead athletes [1]. According to a domestic study, glenohumeral joint injury accounts for nearly $65 \%$ of all injuries among Korean teenage baseball players [2]. High school baseball players are exposed to risks through excessive training and a 
large number of games, due to the pressure of getting accepted into the elite schools or teams. Moreover, the lack of recognition of an injury is a risk factor for even further injury, through aggravation of the previous injury which was not treated appropriately [3]. Repeated pitching elicits changes in the joint of the throwing shoulder (Tshoulder), including increased external rotation (ER) and decreased internal rotation (IR), compared to the nonthrowing shoulder (NT-shoulder) [4-6]. The difference of $\geq 20^{\circ}$ in the range of motion (ROM) in IR between the Tshoulder and the NT-shoulder is known as glenohumeral internal rotation deficit (GIRD) [7,8]. GIRD is a major risk factor for glenohumeral joint injury in baseball players [7,9-11]. GIRD causes humeral retroversion, hyperplasia of the joint capsule, and muscular stiffness; and it induces imbalance in the soft tissues of the shoulder joint, which results in subacromial and intrinsic impingement syndromes $[8,12]$. Wilk et al. [10] reported that the incidence of glenohumeral joint injury is twice as high in baseball players with GIRD, as in those without GIRD. The incidence of GIRD is known to be closely associated with the number and period of overhead throws. In a 10-year study by Fleisig et al. [13] on the pitchers who had thrown more than 100 innings in a year, $5 \%$ of these pitchers were reported to have sustained severe damage and that limiting the number of pitches can reduce the damage. A baseball player is at the risk of shoulder ROM deformation, pain, or damage throughout his career, due to the nature of the sport. As a result of these changes, GIRD may negatively affect the playing span of a baseball player. Although research regarding GIRD has been previously conducted, the associations between the degree of GIRD and shoulder pain and isokinetic strength have not been previously investigated for Korean teenagers, who have not yet reached their full growth potential. Therefore, in the present study, we aimed to determine the degree of GIRD in high school baseball players in Korea and investigated its association with body pain (including shoulder pain), shoulder isokinetic strength, and quality of life.

\section{MATERIALS AND METHODS}

\section{Subjects}

Participants for this study included 61 male players from 2 high-ranking, elite high school baseball teams in the capital region of Seoul. The study procedures were thoroughly explained to the subjects. A simple survey on body pain and quality of life was given, and anthropometry examination was conducted. Participants with a history of shoulder subluxation or surgery were excluded from the study. Physical examinations and ultrasonography evaluations of the shoulder joint for all subjects were performed by a single doctor who was a specialist in rehabilitation medicine. All subjects included in this study were confirmed to have no abnormal neurologic findings in the bilateral upper extremities by the physical examination, and they had no abnormal structures in the shoulder region according to ultrasonography. Five individuals with a history of shoulder surgery (2 elbow fractures, 1 elbow ligament injury, and 2 shoulder dislocations) were excluded; thus, a total of 56 players met the inclusion criteria and were enrolled in the study. The shoulder ROM in all players was measured by a single doctor who was a specialist in rehabilitation medicine. Participants with a difference in the IR ROM of $\geq 20^{\circ}[11,14]$, between the NT-shoulder and the T-shoulder, were assigned to group $\mathrm{A}$; and those with a difference of $<20^{\circ}$ were assigned to group B. Group A included 12 subjects with the following characteristics: a mean age of $16.92 \pm 0.79$ years; height of $176.39 \pm 5.21 \mathrm{~cm}$; weight of $71.09 \pm 4.93 \mathrm{~kg}$; body mass index (BMI) of $22.88 \pm 1.76 \mathrm{~kg} / \mathrm{m}^{2}$; and the mean duration of playing baseball of $6.00 \pm 1.29$ years. Group B included 44 subjects with the following characteristics: a mean age of $16.77 \pm 0.96$ years; height of $177.64 \pm 6.31 \mathrm{~cm}$; weight of $71.09 \pm 4.93 \mathrm{~kg}$; BMI of $22.86 \pm 2.15 \mathrm{~kg} / \mathrm{m}^{2}$; and the mean duration of playing baseball of $6.56 \pm 1.28$ years. The mean age, height, body weight, BMI, and duration of playing baseball were not different between the two groups (Table 1).

Table 1. Demographic characteristics of subjects

\begin{tabular}{lrr}
\hline \multicolumn{1}{c}{ Characteristic } & $\begin{array}{c}\text { Group A } \\
(\mathbf{n = 1 2})\end{array}$ & $\begin{array}{c}\text { Group B } \\
(\mathbf{n}=\mathbf{4 4})\end{array}$ \\
\hline Age $(\mathrm{yr})$ & $16.92 \pm 0.79$ & $16.77 \pm 0.96$ \\
Height $(\mathrm{cm})$ & $176.39 \pm 5.21$ & $177.64 \pm 6.31$ \\
Weight $(\mathrm{kg})$ & $71.09 \pm 4.93$ & $71.09 \pm 4.93$ \\
Body mass index $\left(\mathrm{kg} / \mathrm{m}^{2}\right)$ & $22.88 \pm 1.76$ & $22.86 \pm 2.15$ \\
$\begin{array}{l}\text { Mean duration of } \\
\text { playing baseball }(\mathrm{yr})\end{array}$ & $6.00 \pm 1.29$ & $6.56 \pm 1.28$ \\
\hline
\end{tabular}

Values are presented as mean \pm standard deviation. 


\section{Methods}

\section{Shoulder range of motion measurement}

The shoulder ROM measurements were performed in the morning prior to training so that the soft tissue elasticity and muscle fatigue would not affect the joint angle ROM. The participants were placed in the supine position on the measurement table, and the glenohumeral joint to be measured was exposed towards the edge of the table to avoid ROM restrictions. The subject's shoulder was abducted to $90^{\circ}$ and the elbow was flexed to $90^{\circ}$; one examiner fixed the glenohumeral bone in the glenohumeral joint to be measured, while another examiner measured the IR ROM of the isolated glenohumeral joint on the sagittal plane using standard goniometry [15]. At this time, the fulcrum of the goniometer was placed on the olecranon process, the stationary arm was aligned parallel to the plane, and the moving arm was aligned between the styloid and olecranon processes. The aforementioned methods were repeated for the measurements of shoulder ER ROM.

\section{Shoulder isokinetic strength measurement}

An examiner who was trained at the Korea Institute of Sports Science conducted the shoulder isokinetic strength measurement using the HUMAC/NORM Testing \& Rehabilitation System (Computer Sports Medicine Inc., Stoughton, MA, USA). With the participants in the supine position on the measurement table, a seatbelt and a shoulder stabilizer belt were used to minimize any body movement other than that of the glenohumeral joint. The test tables were aligned, and the lengths of the tables were adjusted to prevent the subject from performing a handgrip action during elbow flexion. The glenohumeral joint shaft of the subjects and the dynamometer shaft were matched, by using the shoulder ROM of the subjects as the reference range. The exercise included measuring the shoulder ROM from the maximum position of flexion to the maximum position of extension. To obtain the flexion and extension isokinetic strengths in the T-shoulder and NT shoulder, the participants were trained through 3 repetitions of the full active ROM at angular velocities of $60^{\circ} \%$ and $180^{\circ} / \mathrm{s}$, respectively. After adequate rest, the exercise was repeated 3 times, and the mean of the 3 measurements was calculated. The measured values were recorded in the built-in software application Patient Setup Window [16] (Fig. 1).

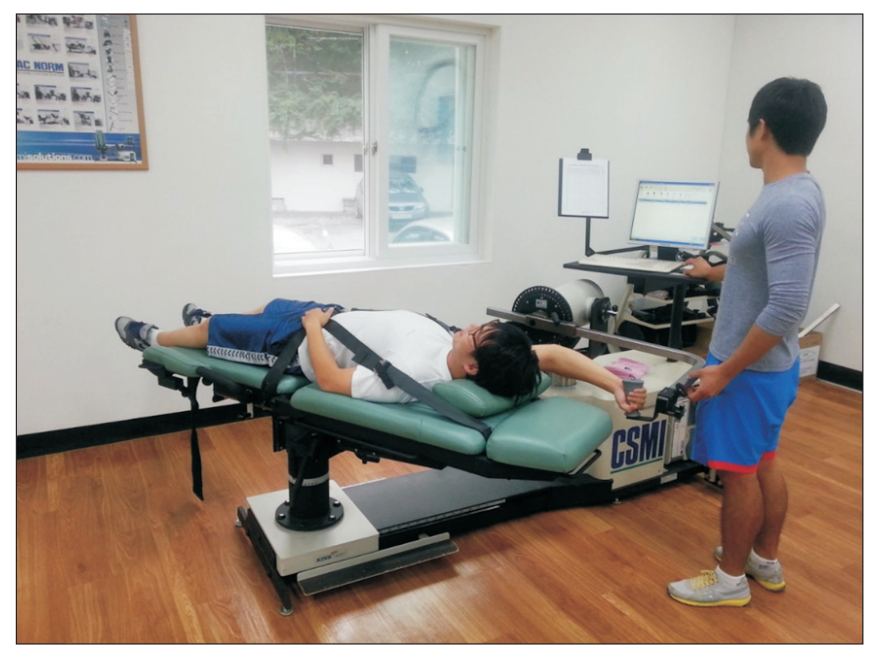

Fig. 1. Shoulder isokinetic strength measurement using the HUMAC/NORM Testing \& Rehabilitation System. This system was used to assess the isokinetic strength of the shoulder flexion and extension, with participants in the supine position and the hip and trunk stabilized by a seatbelt and a shoulder stabilizer belt. The exercise included the measurement of the shoulder range of motion from the maximum position of flexion to the maximum position of extension. This test was repeated 3 times, and the mean of the 3 measurements was calculated at angular velocities of $60^{\circ} / \mathrm{s}$ and $180^{\circ} / \mathrm{s}$.

\section{Pain and quality of life}

Surveys about body pain and the quality of life were conducted by structured questionnaires. The subjects could choose up to 3 body parts that were in pain, out of a list of 6 upper body parts (neck, upper back, shoulder, elbow, wrist, and finger) and 6 lower body parts (lower back, hip, thigh, knee, ankle, and toe). The severity of pain was measured by using a visual analogue scale (VAS). Sufficient explanation regarding the VAS was provided prior to the administration of questionnaires to aid the responder's understanding of the VAS. The survey for assessing the quality of life was conducted by using the 36item Short-Form (SF-36) Health Survey questionnaire [17].

\section{Statistical analysis}

Statistical analysis was performed using SPSS ver.18.0 for Windows (SPSS Inc., Chicago, IL, USA). Variables were presented as mean \pm standard deviation. Descriptive statistics were used for demographic characteristics, ROM, GIRD, and isokinetic strength variables. The 
Mann-Whitney U test was used to compare demographic characteristics, isokinetic strength, pain, and SF-36 responses between groups A and B. The Wilcoxon signedrank test was used to compare the ER ROM and IR ROM between the T-shoulder and the NT-shoulder in all subjects. Statistical significance was set at $\mathrm{p}<0.05$.

\section{RESULTS}

For all subjects, the mean value of ER ROM was significantly higher for the T-shoulder $\left(108.21^{\circ} \pm 10.52^{\circ}\right)$ than for the NT-shoulder $\left(99.12^{\circ} \pm 9.55^{\circ}\right)(\mathrm{p}<0.001)$. The IR ROM was significantly lower for the T-shoulder $\left(39.25^{\circ} \pm 15.29^{\circ}\right)$ than for the NT-shoulder $\left(48.57^{\circ} \pm 12.81^{\circ}\right)(\mathrm{p}<0.001)$. The proportion of individuals with GIRD (12/56 study subjects) was $21.43 \%$. The mean difference in IR ROM, between the NT-shoulder and T-shoulder, was $25.75^{\circ} \pm 1.21^{\circ}$ in group $\mathrm{A}$ and $4.20^{\circ} \pm 11.6^{\circ}$ in group $\mathrm{B}$.

With regard to the ROM of the glenohumeral joint in group A, the mean ER ROM was $106.92^{\circ} \pm 11.37^{\circ}$ in the Tshoulder and $95.67^{\circ} \pm 10.26^{\circ}$ in the NT-shoulder, whereas the mean IR ROM was $29.25^{\circ} \pm 12.98^{\circ}$ in the T-shoulder and $55.00^{\circ} \pm 11.77^{\circ}$ in the NT-shoulder. In group B, the mean ER ROM was $108.57^{\circ} \pm 10.39^{\circ}$ in the T-shoulder

Table 2. The mean differences in the shoulder range of motion and glenohumeral internal rotation deficit between groups A and B

\begin{tabular}{|c|c|c|c|}
\hline & $\begin{array}{c}\text { Total } \\
(n=56)\end{array}$ & $\begin{array}{c}\text { Group A } \\
(n=12)\end{array}$ & $\begin{array}{c}\text { Group B } \\
(\mathrm{n}=\mathbf{4 4})\end{array}$ \\
\hline \multicolumn{4}{|l|}{ ER ROM } \\
\hline T-shoulder $\left({ }^{\circ}\right)$ & $108.21 \pm 10.52$ & $106.92 \pm 11.37$ & $108.57 \pm 10.39$ \\
\hline NT-shoulder $\left({ }^{\circ}\right)$ & $99.12 \pm 9.55$ & $95.67 \pm 10.26$ & $100.07 \pm 9.25$ \\
\hline p-value & $0.000^{*}$ & - & . \\
\hline \multicolumn{4}{|l|}{ IR ROM } \\
\hline T-shoulder $\left({ }^{\circ}\right)$ & $39.25 \pm 15.29$ & $29.25 \pm 12.98$ & $41.98 \pm 14.77$ \\
\hline NT-shoulder $\left({ }^{\circ}\right)$ & $48.57 \pm 12.81$ & $55.00 \pm 11.77$ & $46.82 \pm 12.63$ \\
\hline $\mathrm{p}$-value & $0.000^{*}$ & - & - \\
\hline $\begin{array}{l}\text { Glenohumeral } \\
\text { IR deficit }\end{array}$ & $8.82 \pm 13.56$ & $25.75 \pm 1.21$ & $4.20 \pm 11.36$ \\
\hline
\end{tabular}

Values are presented as mean \pm standard deviation. ER, external rotation; IR, internal rotation; ROM, range of motion; T-shoulder, throwing shoulder; NT-shoulder, non-throwing shoulder.

Glenohumeral IR deficit $=($ IR ROM of the non-throwing shoulder) - (IR ROM of the throwing shoulder). ${ }^{*} \mathrm{p}<0.05$. and $100.07^{\circ} \pm 9.25^{\circ}$ in the NT-shoulder, whereas the mean IR ROM was $41.98^{\circ} \pm 14.77^{\circ}$ in the T-shoulder and $46.82^{\circ} \pm 12.63^{\circ}$ in the NT-shoulder (Table 2).

With regard to the isokinetic strength, at an angular velocity of $60^{\circ} / \mathrm{s}$, the flexion in groups A and B was $73.75 \pm 12.08 \mathrm{~N} / \mathrm{m}$ and $77.70 \pm 9.59 \mathrm{~N} / \mathrm{m}$, respectively, whereas the extension in groups A and B was $94.50 \pm 12.32$ $\mathrm{N} / \mathrm{m}$ and $95.91 \pm 11.41 \mathrm{~N} / \mathrm{m}$, respectively. At an angular velocity of $180^{\circ} / \mathrm{s}$, the flexion in groups $\mathrm{A}$ and B was $73.83 \pm 8.41 \mathrm{~N} / \mathrm{m}$ and $80.32 \pm 9.21 \mathrm{~N} / \mathrm{m}$, respectively, whereas the extension in groups $\mathrm{A}$ and $\mathrm{B}$ was $99.75 \pm 8.34$ $\mathrm{N} / \mathrm{m}$ and $105.84 \pm 9.75 \mathrm{~N} / \mathrm{m}$, respectively (Table 3 ). Increasing severity of GIRD was significantly and negatively correlated with isokinetic strength $(\mathrm{p}<0.001$; correlation coefficient [CC], -0.43 to -0.19 ).

The questionnaires regarding body pain yielded 57 responses; 19 participants (33.33\%) were observed to have shoulder pain, which represented the highest frequency of pain among the body parts studied. Shoulder pain was reported by 3 out of 12 subjects $(25.00 \%)$ in group A and by 19 out of 45 subjects (35.56\%) in group B. With regard to the degree of shoulder pain, the related mean VAS score was $4.67 \pm 3.51$ in group A and $3.5 \pm 1.93$ in group B; however, the difference in these values was not statistically significant. Although the proportion of subjects who reported shoulder pain was lower in group A than in group $B$, the degree of shoulder pain was higher in group $A$, as evidenced by the higher mean VAS scores. In group A, 9 subjects reported of pain in the upper body parts (i.e., neck, upper back, shoulder, elbow, wrist, and finger) and 3 subjects reported of pain in the lower body parts (i.e., lower back, hip, thigh, knee, ankle, and toe), indicating a higher frequency of pain in the upper body compared

Table 3. The mean difference in isokinetic strength of the throwing shoulder between groups A and B (unit, N/m)

\begin{tabular}{lccc}
\hline & $\begin{array}{c}\text { Group A } \\
(\mathbf{n}=\mathbf{1 2})\end{array}$ & $\begin{array}{c}\text { Group B } \\
(\mathbf{n}=\mathbf{4 4})\end{array}$ & p-value \\
\hline $60^{\circ}$ s angular velocity & & & \\
Flexion & $73.75 \pm 12.08$ & $77.70 \pm 9.59$ & 0.528 \\
\hline Extension & $94.50 \pm 12.32$ & $95.91 \pm 11.41$ & 0.630 \\
$180^{\circ} /$ s angular velocity & & & \\
Flexion & $73.83 \pm 8.41$ & $80.32 \pm 9.21$ & $0.025^{*}$ \\
Extension & $99.75 \pm 8.34$ & $105.84 \pm 9.75$ & $0.041^{*}$ \\
\hline
\end{tabular}

Values are presented as mean \pm standard deviation. ${ }^{*} \mathrm{p}<0.05$. 
Table 4. Pain frequency and severity

\begin{tabular}{|lcccc}
\hline \multirow{2}{*}{ Location } & \multicolumn{2}{c}{ Group A (n=12) } & \multicolumn{2}{c}{ Group B (n=44) } \\
\cline { 2 - 5 } & $\begin{array}{c}\text { Pain } \\
\text { frequency }\end{array}$ & VAS & $\begin{array}{c}\text { Pain } \\
\text { frequency }\end{array}$ & VAS \\
\hline Upper body & & & & \\
\hline Neck & 1 & 2 & 0 & - \\
\hline Upper back & 1 & 1 & 0 & - \\
\hline Shoulder & 3 & $4.67 \pm 3.51$ & 16 & $3.50 \pm 1.93$ \\
\hline Elbow & 1 & 2 & 5 & $3.20 \pm 2.17$ \\
\hline Wrist & 2 & 3.5 & 1 & 7 \\
\hline Finger & 1 & 1 & 1 & 1 \\
\hline Lower body & & & & \\
\hline Lower back & 0 & - & 10 & $3.30 \pm 1.89$ \\
\hline Hip & 1 & 6 & 2 & $2.50 \pm 2.12$ \\
\hline Thigh & 0 & - & 2 & 1 \\
\hline Knee & 2 & $3.50 \pm 2.12$ & 6 & $4.50 \pm 1.52$ \\
\hline Ankle & 0 & - & 1 & 3 \\
\hline Toe & 0 & - & 1 & 3 \\
\hline Total & 12 & - & 46 & - \\
\hline Values arepres & & & \\
\hline
\end{tabular}

Values are presented as mean \pm standard deviation.

VAS, visual analogue scale.

to lower body parts (ratio of 3:1). In group B, 23 subjects reported of pain in the upper body parts and 22 subjects reported of pain in lower body parts, indicating similar frequencies of pain for the upper and lower body parts (ratio of 1.05:1) (Table 4). Increasing severity of GIRD was negatively correlated with shoulder pain (CC, -0.22), although this was not statistically significant $(\mathrm{p}=0.14)$.

The sum of the scores for the SF-36 responses was 90.45 in group A and 98.78 in group B, indicating a lower quality of life in group A than group B. In particular, a significant difference was observed for body pain $(\mathrm{p}=0.006)$, social function $(\mathrm{p}=0.007)$, and physical health $(\mathrm{p}=0.017)$ (Table 5). All were negatively correlated with increasing severity of GIRD (CC, -0.25 to -0.13 ).

\section{DISCUSSION}

In this study, a significant relationship was observed between GIRD and pain, isokinetic strength, and the quality of life, among domestic high school male baseball players. Although many international papers have been published regarding GIRD in youth baseball players, only a few papers have been published in Korea. Our study was unique compared to other research studies that in-
Table 5. The mean difference in the quality of life between groups A and B

\begin{tabular}{lllc}
\hline & Group A & Group B & p-value \\
\hline PF & $51.58 \pm 5.97$ & $53.56 \pm 4.66$ & 0.231 \\
RP & $46.88 \pm 10.32$ & $50.98 \pm 6.29$ & 0.307 \\
BP & $43.25 \pm 6.25$ & $51.05 \pm 9.69$ & $0.006^{*}$ \\
GH & $49.41 \pm 8.15$ & $49.16 \pm 8.57$ & 0.944 \\
VT & $47.93 \pm 11.15$ & $47.40 \pm 8.47$ & 0.904 \\
SF & $46.38 \pm 10.24$ & $52.60 \pm 6.73$ & $0.007^{*}$ \\
RE & $43.57 \pm 10.20$ & $47.05 \pm 10.28$ & 0.239 \\
MH & $42.48 \pm 11.22$ & $44.51 \pm 10.52$ & 0.554 \\
\hline PCS & $47.65 \pm 8.63$ & $53.66 \pm 5.95$ & $0.017^{*}$ \\
MCS & $42.80 \pm 11.65$ & $45.12 \pm 9.29$ & 0.632 \\
\hline
\end{tabular}

Values are presented as mean \pm standard deviation.

PF, physical function; RP, role-physical; BP, body pain; $\mathrm{GH}$, general health; VT, vitality; SF, social functioning; $\mathrm{RE}$, role-mental; $\mathrm{MH}$, mental health; PCS, physical component scale; MCS, mental component scale. ${ }^{*} \mathrm{p}<0.05$.

volved a comparative analysis between the quality of life and pain in GIRD group.

In this study, we investigated on how GIRD is correlated with isokinetic strength, pain, and the quality of life in teenage male baseball players. In most of the study subjects, the ER ROM of the T-shoulder was greater than that of the NT-shoulder, while the IR ROM of the T-shoulder was lesser than that of the NT-shoulder. Considering that GIRD is a shoulder pathologic risk factor, Burkhart et al. [14] reported that glenohumeral joint damage increases when the IR ROM deficit of the T-shoulder is $\geq 20^{\circ}$ compared to that of the NT-shoulder. Participants with an IR ROM difference of $\geq 20^{\circ}$ between the T-shoulder and the NT-shoulder were assigned to group A, which accounted for $21.43 \%$ of the total subjects in this study. According to the isokinetic strength test, a weaker muscular state was observed in group A compared to group B. Compared to pain in other body parts, the frequency of shoulder pain was the highest (33.93\%) among the study subjects. A lower quality of life was also observed in group A compared to group $\mathrm{B}$, according to the evaluations using the SF-36.

Repeated high-velocity pitching causes a change in the stability-mobility relationship of the glenohumeral joint. Characteristically, the ER ROM of the T-shoulder increases, whereas the IR ROM tends to decrease, lead- 
ing to an increased difference in IR ROM between the Tshoulder and NT shoulder [4-6]. An excessively increased ER increases the humeral retroversion, thus causing an IR deficit $[4,5]$. Over time, this pathogenic mechanism leads to the high prevalence of posterior capsular contracture in the T-shoulder. The interface between the humerus and the glenoid gradually shifts in the posterior direction and subsequently leads to a posterior shift of the total arc of motion in the glenohumeral joint $[14,16]$. Consequently, the anterior length of the capsule increases, and the surface area in contact with the anterior-inferior aspect of the glenohumeral joint decreases, which results in an excessive ER [7]. Therefore, the balance between the IR and ER ROM in the total glenohumeral joint ROM is disrupted [17,18]. Wilk et al. [6] measured the ROM of the T-shoulder in a study of 372 baseball players; in the Tshoulder, the ER ROM was greater and the IR ROM was smaller compared to the NT-shoulder. The results of the present study are compatible with the typical shoulder joint characteristics of baseball players.

In this study, $21.43 \%$ of the subjects were included in group A. In a previous study by Shanley et al. [15], the prevalence of GIRD among baseball players was reported to be nearly $25 \%$ ( 18 out of 72 individuals). Our results are similar to these previous findings. In a study of collegiate baseball pitchers and non-pitching players, Cook et al. [16] investigated the isokinetic strength of the shoulder flexion and extension and highlighted the importance of shoulder strength balance. The isokinetic strength was closely associated with ROM, and improving the ROM limits was reported to increase joint torque and shoulder performance $[17,18]$. In the isokinetic strength test, the results obtained at an angular velocity of $180^{\circ} / \mathrm{s}$ are more closely related to the throwing conditions for baseball, where the ball is pitched at a high velocity; this indicates that the limited shoulder ROM may negatively affect performance. In previous studies on GIRD, a considerable amount of research has focused on isokinetic strength of shoulder IR and ER, whereas research on isokinetic strength related to other conditions, such as shoulder flexion or extension, is few. In our study, there was a negative correlation between GIRD and isokinetic strength, which suggests that the isokinetic strength was reduced as GIRD was increased. These findings will enable us to design an effective rehabilitation program for balanced strength, by considering the factors such as muscular im- balance due to shoulder injury.

It has been previously reported that the incidence of glenohumeral joint pain in baseball players was $32 \%$, with overuse being the main cause of such pain $[19,20]$. Surgical treatment for damages in high school pitchers has been reported to have increased from $8 \%$ to $24 \%$ over the last 10 years [21]. Noffal [22] reported that the imbalance of rotator cuff muscles induces muscular dysfunction, thereby creating conditions that easily lead to pain or glenohumeral joint injury. In this study, $33.33 \%$ of the subjects reported of shoulder pain, which was similar to previous studies. Interestingly, group A showed a lower frequency of shoulder pain than group B, although the ratio of upper body pain was higher. The throwing motion of the baseball players comprises a series of movements involving the torso, shoulder, elbow, wrist, and fingers. Therefore, the high frequency of upper body pain compared to lower body pain may have been affected by the limited shoulder ROM. Group A had a low quality of life and performance, but the quality of life could be improved through shoulder ROM improvement via an appropriate shoulder joint rehabilitation program. Shanley et al. [15], who compared the pre- and post-baseball seasons reported that GIRD increased by approximately $7^{\circ}$ in the post-season compared to the pre-season values. The present study was conducted in the preseason. Therefore, there is a high probability that the incidence of pain or damage, including the glenohumeral ROM, will increase as the season progresses.

Our study has three limitations. First, because the study subjects had a large amount of team training schedules to prepare for the upcoming high school baseball season, there was a limitation in mustering them for repeated measures of ROM and isokinetic strength. As a mean to reduce bias, the measurements were performed by one doctor of physical rehabilitation in the morning prior to training. According to previous studies [10,15], the ROM measurement methods used in this research showed good reliability and validity. Also, the isokinetic measurement using Cybex is an objective testing device commonly used in sports and orthopedic fields in the world. Its reliability and validity are well documented [23]. Secondly, in the present study, we were unable to measure the isokinetic strength of shoulder IR and ER, due to limited manpower and equipment; therefore, we only evaluated the isokinetic strength of shoulder flexion and extension. 
Thirdly, this study was conducted in the preseason and the results may not be applicable to the season or postseason conditions [2,24].

The glenohumeral joint is easily subjected to damage in baseball players. The American Medical Society for Sports Medicine has recommended monitoring of the development and training intensity in teenage athletes to reduce their risk factors for damages and using appropriate diagnosis and rehabilitation programs in response to the damages [3]. In this study, GIRD showed a statistically significant and negative correlation with muscle power or isokinetic strength, and it is thought to be related with a decrease in muscle strength and quality of life for male high school baseball players. The group with GIRD was observed to have lower muscle strength, lower quality of life score, and a higher frequency of upper body pain than the non-GIRD group.

\section{CONFLICT OF INTEREST}

No potential conflict of interest relevant to this article was reported.

\section{ACKNOWLEDGMENTS}

This work was performed with financial support from the sports promotion fund, the Korea Institute of Sport Science, Korea Sports Promotion Foundation (No. KISS2012-15).

\section{REFERENCES}

1. Laudner K, Sipes R. The incidence of shoulder injury among collegiate overhead athletes. J Intercoll Sport 2009;2:260-8.

2. Yoon JS. A study on sport injuries of the baseball player's position [dissertation]. Seoul: Kookmin University; 2006.

3. DiFiori JP, Benjamin HJ, Brenner JS, Gregory A, Jayanthi N, Landry GL, et al. Overuse injuries and burnout in youth sports: a position statement from the American Medical Society for Sports Medicine. Br J Sports Med 2014;48:287-8.

4. Crockett HC, Gross LB, Wilk KE, Schwartz ML, Reed J, O'Mara J, et al. Osseous adaptation and range of motion at the glenohumeral joint in professional baseball pitchers. Am J Sports Med 2002;30:20-6.

5. Osbahr DC, Cannon DL, Speer KP. Retroversion of the humerus in the throwing shoulder of college baseball pitchers. Am J Sports Med 2002;30:347-53.

6. Wilk KE, Meister K, Andrews JR. Current concepts in the rehabilitation of the overhead throwing athlete. Am J Sports Med 2002;30:136-51.

7. Burkhart SS, Morgan CD, Kibler WB. The disabled throwing shoulder: spectrum of pathology. Part II: Evaluation and treatment of SLAP lesions in throwers. Arthroscopy 2003;19:531-9.

8. Kibler WB, Sciascia A, Thomas SJ. Glenohumeral internal rotation deficit: pathogenesis and response to acute throwing. Sports Med Arthrosc 2012;20:34-8.

9. Seroyer ST, Nho SJ, Bach BR Jr, Bush-Joseph CA, Nicholson GP, Romeo AA. Shoulder pain in the overhead throwing athlete. Sports Health 2009;1:108-20.

10. Wilk KE, Macrina LC, Fleisig GS, Porterfield R, Simpson CD 2nd, Harker P, et al. Correlation of glenohumeral internal rotation deficit and total rotational motion to shoulder injuries in professional baseball pitchers. Am J Sports Med 2011;39:329-35.

11. Braun S, Kokmeyer D, Millett PJ. Shoulder injuries in the throwing athlete. J Bone Joint Surg Am 2009;91:966-78.

12. Ticker JB, Beim GM, Warner JJ. Recognition and treatment of refractory posterior capsular contracture of the shoulder. Arthroscopy 2000;16:27-34.

13. Fleisig GS, Andrews JR, Cutter GR, Weber A, Loftice J, McMichael C, et al. Risk of serious injury for young baseball pitchers: a 10-year prospective study. Am J Sports Med 2011;39:253-7.

14. Burkhart SS, Morgan CD, Kibler WB. The disabled throwing shoulder: spectrum of pathology. Part I: Pathoanatomy and biomechanics. Arthroscopy 2003;19:404-20.

15. Shanley E, Thigpen CA, Clark JC, Wyland DJ, Hawkins RJ, Noonan TJ, et al. Changes in passive range of motion and development of glenohumeral internal rotation deficit (GIRD) in the professional pitching shoulder between spring training in two consecutive years. J Shoulder Elbow Surg 2012;21:1605-12.

16. Cook EE, Gray VL, Savinar-Nogue E, Medeiros J. Shoulder antagonistic strength ratios: a comparison between college-level baseball pitchers and nonpitchers. J Orthop Sports Phys Ther 1987;8:451-61. 
17. Abdel-Aziem AA, Mohammad WS. Plantar-flexor static stretch training effect on eccentric and concentric peak torque: a comparative study of trained versus untrained subjects. J Hum Kinet 2012;34:49-58.

18. Mandroukas A, Vamvakoudis E, Metaxas T, Papadopoulos $\mathrm{P}$, Kotoglou K, Stefanidis P, et al. Acute partial passive stretching increases range of motion and muscle strength. J Sports Med Phys Fitness 2014;54:28997.

19. Lyman S, Fleisig GS, Waterbor JW, Funkhouser EM, Pulley L, Andrews JR, et al. Longitudinal study of elbow and shoulder pain in youth baseball pitchers. Med Sci Sports Exerc 2001;33:1803-10.

20. Lyman S, Fleisig GS, Andrews JR, Osinski ED. Effect of pitch type, pitch count, and pitching mechanics on risk of elbow and shoulder pain in youth baseball pitchers. Am J Sports Med 2002;30:463-8.
21. Dun S, Loftice J, Fleisig GS, Kingsley D, Andrews JR. A biomechanical comparison of youth baseball pitches: is the curveball potentially harmful? Am J Sports Med 2008;36:686-92.

22. Noffal GJ. Isokinetic eccentric-to-concentric strength ratios of the shoulder rotator muscles in throwers and nonthrowers. Am J Sports Med 2003;31:537-41.

23. Sapega AA, Drillings G. The definition and assessment of muscular power. J Orthop Sports Phys Ther 1983;5:7-9.

24. Kaplan KM, Elattrache NS, Jobe FW, Morrey BF, Kaufman KR, Hurd WJ. Comparison of shoulder range of motion, strength, and playing time in uninjured high school baseball pitchers who reside in warm- and cold-weather climates. Am J Sports Med 2011;39:320-8. 